\title{
O SISTEMA GERAL DE PREFERÊNCIAS DOS EUA: \\ UMA ESTIMATIVA DOS IMPACTOS SOBRE AS EXPORTAÇÕES BRASILEIRAS*
}

\author{
Natalia Paiva do Nascimento Visconti ${ }^{* *}$
}

\section{Honorio Kume}

RESUMO O Sistema Geral de Preferências (SGP) dos EUA, concedido de forma unilateral, é um dos programas com tarifa preferencial mais importantes para o Brasil, mas recentemente vem sendo objeto de apreensão devido às ameaças de exclusão do Brasil entre os países beneficiários. Este trabalho tem como objetivo estimar, com base no modelo de equilíbrio parcial computável, a perda das exportações brasileiras para os EUA se o Brasil for eliminado do SGP. Os resultados obtidos indicam uma queda nas exportações de aproximadamente US\$ 403 milhões, sendo concentrada em um pequeno número de setores.

Palavras-chave: Sistema Geral de Preferências (SGP); modelo de equilíbrio parcial; exportações brasileiras

Código JEL: F13

THE U.S. GENERALIZED SYSTEM OF PREFERENCES: AN ESTIMATE OF THE IMPACTS ON BRAZILIAN EXPORTS

\footnotetext{
ABSTRACT The U.S. Generalized System of Preferences (GSP), a concession offered unilaterally, is one of the most important preferential tariff programs to Brazil, but recently has been causing some apprehension due to threats to exclude this country from the list of beneficiaries. This study has the objective to estimate, based on the

* Artigo enviado em 24 de abril de 2008 e aprovado em 10 de março de 2010. Os autores agradecem as sugestões e os comentários de Guida Piani e de dois pareceristas anônimos que permitiram corrigir erros e contribuíram para o aperfeiçoamento geral do trabalho.

** Mestre pelo Programa de Pós-graduação da Faculdade de Ciências Econômicas da Universidade do Estado do Rio de Janeiro, e-mail: natalia@norwan.com.br

*** Professor adjunto da UERJ e pesquisador do Ipea, e-mail: honorio.kume@ipea.gov.br
} 
partial computational equilibrium model, the loss of the brazilian exports to the USA if Brazil is excluded from the GSP. The results obtained imply a decrease of US\$ 403 millions of exports, concentrated on a small number of sectors.

Key words: Generalized System of Preferences (GSP); partial equilibrium model; brazilian exports 


\section{INTRODUÇÃO}

Desde os anos 1970, os países desenvolvidos - 11 nações e a União Europeia - têm oferecido, de forma unilateral, diversos programas que concedem preferências tarifárias para as importações provenientes de países em desenvolvimento, entre os quais o Sistema Geral de Preferências (SGP) é um dos mais importantes. ${ }^{1}$

Nos EUA, o SGP proporciona uma redução tarifária de 100\%, condicionada ao cumprimento de determinados requisitos, beneficiando 144 países e territórios, entre eles o Brasil. Esse instrumento é renovado periodicamente por três anos.

As exportações brasileiras totais para os EUA atingiram US\$ 31 bilhões, em 2006, dos quais 14,3\% foram efetuados com os benefícios do SGP, alcançando US\$ 3,7 bilhões. O Brasil situa-se na quarta posição entre os maiores países exportadores nesse programa.

No entanto, como é uma medida unilateral, os EUA podem excluir um país da lista de beneficiados caso considere, dentre outros fatores, ${ }^{2}$ que ele não está fornecendo a proteção adequada aos direitos de propriedade intelectual norte-americanos. Assim, na época da renovação do SGP em 2006, o Brasil foi ameaçado de exclusão devido às investigações iniciadas em 2001 com base em uma petição da International Intellectual Property Rights Alliance (IIPA), ${ }^{3}$ que levou o United States Trade Representative (USTR) a incluir o Brasil na Priority Watch List do Special 301 Report. ${ }^{4}$ Porém, naquele mesmo ano, o Subcomitê do SGP do Comitê de Política Comercial reconheceu os esforços do país no combate à pirataria e transferiu o Brasil para a Watch List, em 2007.

Dessa forma, em cada época da renovação, os exportadores brasileiros sofrem da incerteza sobre a continuidade das preferências e pressionam o governo para uma mobilização política que evite a exclusão do Brasil. Contudo, esses movimentos são feitos sem uma estimativa que indique qual é a perda nas exportações e quais os setores que serão mais prejudicados.

Há vários trabalhos sobre o impacto do SGP sobre as exportações dos países beneficiários (Dean e Wainio, 2006; Seyoum, 2006), mas sem um enfoque específico para o Brasil, à exceção de Gutierrez (1986), já muito desatualizado para fornecer estimativas confiáveis. 
O objetivo deste trabalho é preencher essa lacuna, estimando o impacto sobre as exportações brasileiras, no período 2004-2006, de uma eventual exclusão do Brasil dentre os beneficiários do SGP dos EUA, com base em um modelo estático de equilíbrio parcial computável. Esse resultado será de grande utilidade para avaliar a importância dessas recorrentes ameaças em cada momento da renovação. Vale advertir, também, que os ganhos de comércio obtidos em modelos estáticos não incorporam as vantagens adicionais que as exportações podem proporcionar, tais como economias de escala e atualização tecnológica exigida para firmas que competem em mercados mundiais.

Além desta breve introdução, o trabalho está organizado da seguinte forma: a seção 1 apresenta uma descrição sucinta do SGP dos EUA e mostra a evolução e a estrutura das exportações brasileiras para os EUA no período 2004-2006; a seção 2 expõe os procedimentos metodológicos adotados na estimação e avalia os resultados; e finalmente, a seção 3 resume as principais conclusões.

\section{O SGP DOS EUA E AS EXPORTAÇÕES BRASILEIRAS}

\subsection{Breve descrição}

O SGP dos EUA entrou em vigor no dia $1^{\circ}$ de janeiro de 1976 sob a autorização do Trade Act de 1974 e favorecia cerca de 4.650 produtos (de acordo com a classificação Harmonized Tariff Schedule of the United States - HTSUS, a oito dígitos), sendo a maioria composta de produtos industrializados. Dois grupos de produtos foram excluídos, um com base no Trade Act de $1974-$ produtos têxteis, ${ }^{5}$ relógios e manufaturados de couro (calçados, bolsas, malas e similares) - e outro por ser considerado sensível à produção domésti$\mathrm{ca}$ - aço, vidro e produtos eletrônicos, entre outros.

Os produtos beneficiados devem cumprir o requisito de origem, segundo o qual o valor total dos insumos domésticos (custo total dos insumos produzidos no país mais o custo direto de processamento ${ }^{6}$ deve ser igual ou superior a $35 \%$ do preço do produto exportado.

O programa distingue duas categorias de países: os menos desenvolvidos e aqueles em desenvolvimento. O primeiro recebe duas vantagens adicionais: a inclusão de mais 1.700 produtos e a isenção dos limites competitivos (LCs). 
O LC é utilizado para impedir o acesso ao programa por parte de países que já possuem competitividade nos produtos em questão, sendo baseado em dois critérios revistos anualmente (Devault, 1996);

(a) LC percentual: se o país beneficiário representa $50 \%$ ou mais do total das importações norte-americanas desse produto; e

(b) LC valor: se o valor de exportação desse bem do país favorecido for igual ou maior do que US\$ 125 milhões. $^{7}$

Assim, com a Revisão Anual do SGP, os EUA podem incluir ou excluir produtos e eliminar os benefícios para determinados países que tenham atingido algum dos LCs. No entanto, esses critérios podem ser ignorados se isenções (waivers) forem concedidas, permitindo que tais produtos continuem recebendo tratamento preferencial.

Existem quatro tipos de isenção: (i) por solicitação do país interessado; (ii) por ausência de produção norte-americana; (iii) por dispensa aos países menos desenvolvidos; e (iv) a isenção de minimus.

O presidente dos EUA pode atender ao pedido de isenção se considerar que o país em questão oferece acesso considerável aos produtos dos EUA e respeita o direito de propriedade intelectual norte-americano, desde que o valor total das importações dos países beneficiados com a isenção não supere 30\% do valor total das importações sob o SGP do ano em questão.

O segundo tipo de isenção é aceito para os produtos que não eram produzidos nos EUA em $1^{\circ}$ de janeiro de 1995, enquanto o terceiro é automaticamente concedido aos países menos desenvolvidos.

Por fim, a isenção de minimus é atendida quando as importações totais do produto são pequenas. O valor mínimo dessas importações em 2006 foi de US\$ 18 milhões, sendo acrescido em US\$ 500 mil a cada ano.

Por último, um país beneficiário pode "graduar-se" do programa, isto é, ser excluído do programa, se for determinado pelo presidente dos EUA que ele se tornou um país de alta renda, baseado nas estatísticas do Banco Mundial. Muitos países, como os países do Leste Asiático, foram eliminados com base nesse critério.

\subsection{As exportações brasileiras no SGP-EUA}

O gráfico 1 apresenta a participação dos produtos favorecidos no SGP no total das exportações brasileiras no mercado norte-americano — média 


\section{Gráfico 1: Participação do SGP nas exportações totais do Brasil para os EUA (\%), média móvel de três anos centrada no ano de referência}

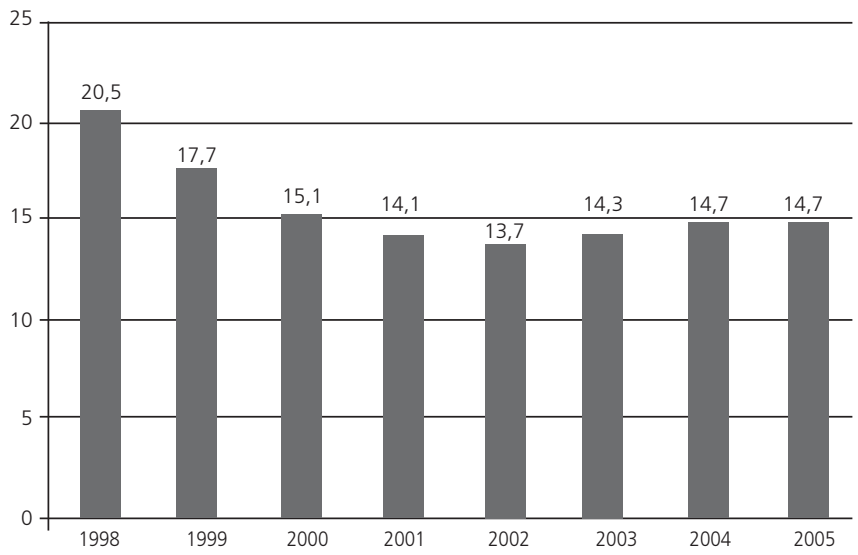

Fonte: United States International Trade Commission (Usitc). Elaboração própria.

Tabela 1: Importações norte-americanas anuais - SGP e total, 15 principais países beneficiários no período total 2004-2006 (US\$ milhões)

\begin{tabular}{|c|c|c|c|c|}
\hline País & SGP & Participação SGP (\%) & Total & SGP/Total (\%) \\
\hline Angola & 4.646 & 17,0 & 8.152 & 57,0 \\
\hline Índia & 4.376 & 16,0 & 18.629 & 23,5 \\
\hline Tailândia & 3.657 & 13,4 & 19.886 & 18,4 \\
\hline Brasil & 3.511 & 12,8 & 23.871 & 14,7 \\
\hline Indonésia & 1.610 & 5,9 & 11.994 & 13,4 \\
\hline Guiné Equatorial & 1.314 & 4,8 & 1.482 & 88,7 \\
\hline Turquia & 1.055 & 3,8 & 5.149 & 20,5 \\
\hline Filipinas & 1.039 & 3,8 & 9.359 & 11,1 \\
\hline África do Sul & 1.011 & 3,7 & 6.426 & 15,7 \\
\hline Venezuela & 748 & 2,7 & 31.158 & 2,4 \\
\hline Argentina & 615 & 2,2 & 4.115 & 15,0 \\
\hline Rússia & 602 & 2,2 & 15.544 & 3,9 \\
\hline Cazaquistão & 283 & 1,0 & 869 & 32,5 \\
\hline Romênia & 259 & 0,9 & 1.056 & 24,6 \\
\hline lêmen & 199 & 0,7 & 258 & 77,3 \\
\hline Subtotal & 24.925 & 91,1 & 157.946 & 15,8 \\
\hline Outros & 2.428 & 8,9 & 1.497 .919 & 0,2 \\
\hline Total & 27.353 & 100,0 & 1.655 .864 & 1,7 \\
\hline
\end{tabular}

Fonte: Usitc. Elaboração própria. 
móvel de três anos centrada no ano de referência — no período 1998-2005. Nota-se que essa parcela é decrescente, passando de 20,5\%, em 1998, para 13,7\%, em 2002. A partir de então, apresenta uma tendência levemente crescente, alcançando 14,7\% no biênio 2004-2005.

A tabela 1 lista os 15 principais países fornecedores dos EUA sob o SGP, indicando a exportação total e aquela beneficiada com tratamento tarifário preferencial no período 2004-2006 (média anual). Pode-se observar que esses países foram responsáveis por $91,1 \%$ das importações norte-americanas nesse programa, refletindo a alta concentração em alguns poucos países. O Brasil ocupa a quarta posição em valores absolutos. No entanto, a sua dependência desse programa atinge 14,7\%, bastante inferior à de países menos desenvolvidos, tais como Angola (com 57\%), Guiné Equatorial (88,7\%) e Iêmen (77,3\%). Para o conjunto dos países listados, a participação do SGP no total das suas vendas para os EUA alcança, em média, 15,8\%. No entanto, no global, as importações norte-americanas no âmbito do SGP correspondem somente a $1,7 \%$ do valor total.

A tabela 2 apresenta o grau de utilização brasileira do SGP-EUA por setor (seção do Sistema Harmonizado), medido pela parcela das exportações brasileiras com isenção tarifária no total das vendas externas do Brasil de produtos potencialmente sujeitos a esse benefício. O grau de utilização por setor varia entre $69,7 \%$ e $99,8 \%$, com média de $83,2 \% .{ }^{8}$ Os benefícios desse programa são mais aproveitados em armas e munições $(99,8 \%)$, peles e couros $(98 \%)$, pérolas e metais preciosos $(97,6 \%)$ e produtos do reino vegetal $(97,4 \%)$, enquanto o menor uso ocorre em máquinas e equipamentos (69,7\%), plásticos e borracha (70\%) e alimentos, bebidas e fumo (70,2\%).

Um grau de utilização inferior a 100\% indica que alguns exportadores brasileiros não se beneficiaram da preferência tarifária, ainda que o produto esteja listado como sujeito ao tratamento favorável no SGP. Esse comportamento pode estar relacionado ao desconhecimento do SGP ou quando o custo de atender ao regime de origem é superior ao ganho proporcionado pela isenção da tarifa. Vale notar que os setores favorecidos com SGP apresentam uma tarifa baixa, em média de 3,7\%, atingindo o máximo de 6,9\% (tabela 2).

A tabela 3 mostra a distribuição por setor das exportações brasileiras no SGP e o grau de cobertura, calculado pela participação das exportações beneficiadas no total das importações tributáveis norte-americanas provenientes do Brasil. 
Tabela 2: Grau de utilização das exportações brasileiras dos produtos beneficiados no SGP-EUA (valor anual médio em US\$ milhões) e tarifa média, 2004-2006

\begin{tabular}{|c|c|c|c|c|c|}
\hline $\begin{array}{c}\text { Setores } \\
\text { (1) }\end{array}$ & $\begin{array}{c}\text { Descrição } \\
(2)\end{array}$ & $\begin{array}{l}\text { SGP } \\
(3)\end{array}$ & $\begin{array}{c}\text { Total } \\
(4)\end{array}$ & $\begin{array}{c}\text { SGP/Total (\%) } \\
(5)\end{array}$ & $\begin{array}{c}\text { Tarifa média (\%) } \\
(6)\end{array}$ \\
\hline 1 & Produtos do reino animal & 1,7 & 1,8 & 90,2 & 5,7 \\
\hline 2 & Produtos do reino vegetal & 35,6 & 36,5 & 97,4 & 4,8 \\
\hline 3 & Óleos animais ou vegetais & 2,2 & 2,5 & 90,9 & 6,0 \\
\hline 4 & Alimentos, bebidas e fumo & 148,2 & 211,0 & 70,2 & 3,7 \\
\hline 5 & Produtos minerais & 9,1 & 9,3 & 97,4 & 2,8 \\
\hline 6 & Produtos químicos & 209,5 & 243,9 & 85,9 & 4,4 \\
\hline 7 & Plásticos e borracha & 221,6 & 316,6 & 70,0 & 4,4 \\
\hline 8 & Peles e couros & 123,9 & 126,5 & 98,0 & 2,9 \\
\hline 9 & Madeira e mobiliário & 518,5 & 601,3 & 86,2 & 6,1 \\
\hline 10 & Celulose e papel & 0,0 & 0,0 & 0,0 & 0,0 \\
\hline 11 & Têxtil e vestuário & 21,7 & 23,1 & 94,1 & 6,4 \\
\hline 12 & Calçados & 0,6 & 0,7 & 88,7 & 3,5 \\
\hline 13 & Cerâmica e vidro & 159,2 & 180,9 & 88,0 & 5,1 \\
\hline 14 & Pedras e metais preciosos & 40,7 & 41,7 & 97,6 & 6,9 \\
\hline 15 & Metais & 693,0 & 719,8 & 96,3 & 3,0 \\
\hline 16 & Máquinas e equipamentos & 778,7 & $1.117,8$ & 69,7 & 2,8 \\
\hline 17 & Material de transporte & 571,2 & 623,3 & 91,6 & 2,5 \\
\hline 18 & Aparelhos de ótica e precisão & 24,2 & 31,6 & 76,7 & 2,2 \\
\hline 19 & Armas e munições & 19,2 & 19,2 & 99,8 & 3,2 \\
\hline \multirow[t]{2}{*}{20} & Diversos & 38,9 & 40,2 & 96,8 & 5,9 \\
\hline & Total & $3.617,5$ & $4.347,6$ & 83,2 & 3,7 \\
\hline
\end{tabular}

Fonte: Usitc. Elaboração própria.

Vale notar que os quatro principais setores com maior valor de exportação no SGP atingem, no acumulado, 70,8\% do total desse programa: máquinas e equipamentos $(21,5 \%)$, metais $(19,2 \%)$, material de transporte $(15,8 \%)$ e madeira e mobiliário $(14,3 \%)$. O grau de cobertura, que indica o quanto das exportações tributáveis é realizado por meio do SGP, mostra uma grande variabilidade por setor. Em peles e couros, metais, pérolas e metais preciosos e instrumentos de ótica e precisão as vendas por meio do SGP superam $70 \%$ do total.

Caso o Brasil venha a perder esses benefícios, os produtos brasileiros atualmente isentos estarão sujeitos ao pagamento da tarifa. A tabela 4 apresenta a distribuição dos produtos e das exportações brasileiras anuais médias no SGP no período 2004-2006, por faixa tarifária. Observa-se que, tanto em 
Tabela 3: Distribuição e grau de cobertura das exportações brasileiras no SGP-EUA, por setor - 2004-2006 (US\$ milhões)

\begin{tabular}{|c|c|c|c|c|c|}
\hline Setor & Descrição & SGP & $\begin{array}{c}\text { Parcela no } \\
\text { SGP total (\%) }\end{array}$ & $\begin{array}{l}\text { Importações } \\
\text { tributáveis }\end{array}$ & $\begin{array}{c}\text { Grau de } \\
\text { cobertura (\%) }\end{array}$ \\
\hline 1 & Produtos do reino animal & 1,6 & 0,0 & 21,8 & 7,5 \\
\hline 2 & Produtos do reino vegetal & 35,6 & 1,0 & 59,3 & 60,0 \\
\hline 3 & Óleos animais ou vegetais & 2,2 & 0,1 & 17,4 & 12,8 \\
\hline 4 & Alimentos, bebidas e fumos & 148,2 & 4,1 & $1.193,6$ & 12,4 \\
\hline 5 & Produtos minerais & 9,1 & 0,3 & $2.494,9$ & 0,4 \\
\hline 6 & Produtos químicos & 209,5 & 5,8 & 459,3 & 45,6 \\
\hline 7 & Plásticos e borracha & 221,5 & 6,1 & 412,8 & 53,6 \\
\hline 8 & Peles e couros & 123,9 & 3,4 & 131,9 & 93,9 \\
\hline 9 & Madeira e mobiliário & 518,5 & 14,3 & 769,8 & 67,3 \\
\hline 10 & Celulose e papel & & - & 109,1 & 0,0 \\
\hline 11 & Têxtil e vestuário & 21,7 & 0,6 & 416,6 & 5,2 \\
\hline 12 & Calçados & 0,6 & 0,0 & 976,0 & 0,1 \\
\hline 13 & Cerâmica e vidro & 159,2 & 4,4 & 718,3 & 22,2 \\
\hline 14 & Pérolas e metais preciosos & 40,7 & 1,1 & 55,6 & 73,2 \\
\hline 15 & Metais & 693,0 & 19,2 & 769,1 & 90,1 \\
\hline 16 & Máquinas e equipamentos & 778,7 & 21,5 & $1.550,3$ & 50,2 \\
\hline 17 & Material de transporte & 571,2 & 15,8 & 954,4 & 59,9 \\
\hline 18 & Aparelhos de ótica e precisão & 24,2 & 0,7 & 31,9 & 76,0 \\
\hline 19 & Armas e munições & 19,2 & 0,5 & 53,3 & 35,9 \\
\hline \multirow[t]{2}{*}{20} & Diversos & 38,9 & 1,1 & 147,6 & 26,3 \\
\hline & Total & $3.617,5$ & 100,0 & $11.343,2$ & 31,9 \\
\hline
\end{tabular}

Fonte: Usitc. Elaboração própria.

Tabela 4: Número de produtos e exportações brasileiras no SGP por faixas tarifárias, 2004-2006 (US\$ milhões)

\begin{tabular}{lcccc}
\hline Tarifa $-\mathrm{T}(\%)$ & $\mathrm{N}^{\circ}$ de produtos & Parcela do total (\%) & Exportação & Parcela do total (\%) \\
\hline $\mathrm{T} \leq 2,5$ & 438 & 23,9 & 384 & 10,9 \\
\hline $2,5<\mathrm{T} \leq 5$ & 906 & 49,4 & 1.943 & 55,3 \\
\hline $5<\mathrm{T} \leq 7,5$ & 380 & 20,7 & 1.110 & 31,6 \\
\hline $7,5<\mathrm{T} \leq 10$ & 65 & 3,5 & 37 & 1,0 \\
\hline $10<\mathrm{T} \leq 12,5$ & 23 & 1,2 & 9 & 0,3 \\
\hline $12,5<\mathrm{T} \leq 15$ & 11 & 0,6 & 26 & 0,8 \\
\hline$T>15$ & 9 & 0,5 & 2 & 0,1 \\
\hline Total & 1.832 & 100,0 & 3.511 & 100,0 \\
\hline
\end{tabular}

Fonte: Usitc. Elaboração própria. 
valor quanto no número de produtos, há uma concentração no intervalo de 2,5 a $5 \%$ (inclusive) e no de 5 a 7,5\% (inclusive), seguido pela faixa de tarifas inferiores a $2,5 \%$.

\section{ESTIMATIVA DOS IMPACTOS SOBRE AS EXPORTAÇÕES BRASILEIRAS}

A estimativa dos impactos de uma eventual eliminação do Brasil do SGP dos EUA sobre as exportações pode ser baseada nos modelos de equilíbrio parcial ou de equilíbrio geral.

O modelo de equilíbrio geral efetua uma simulação, que combina a estrutura representativa de uma economia com dados econômicos realísticos, e os resultados indicam soluções de equilíbrio para os níveis de oferta, demanda e preço em um conjunto de setores especificados. Esse modelo é bastante utilizado nos estudos de comércio internacional (Brown, 1987).

O modelo de equilíbrio parcial busca mensurar o efeito primário de uma mudança específica em um setor ou em um nível mais desagregado, como produtos. Essa análise permite efetuar estimativas por setor ou produto, mas trata cada um isoladamente, não considerando a interdependência entre eles e, assim, os efeitos secundários.

A grande vantagem do modelo de equilíbrio geral é a inclusão das restrições devidas às inter-relações setoriais e das de natureza macroeconômica, isto é, os impactos setoriais consideram tanto os efeitos provocados por cada setor sobre as variáveis macroeconômicas quanto os efeitos destas sobre cada setor (Harrison et al., 2003).

A princípio, o modelo de equilíbrio geral parece ser melhor por levar em consideração esses efeitos secundários. Contudo, a necessidade de se trabalhar com uma classificação setorial muito mais agregada o torna menos atrativo (Laird e Yeats, 1986). A grande vantagem do modelo de equilíbrio parcial é a possibilidade de efetuar estimativas nos níveis setoriais bastante desagregados.

Dado o reduzido valor das exportações brasileiras atualmente beneficiadas pelo programa do SGP norte-americano, os efeitos secundários não são importantes. Portanto, não se justifica o uso de modelos de equilíbrio geral neste trabalho.

Ademais, a possibilidade de uma análise em um nível setorial bastante desagregado (muito importante neste estudo, já que é necessário trabalhar 
no nível de produto na classificação tarifária) que propicia uma maior precisão na identificação dos principais setores afetados foi decisiva na opção pelo modelo de equilíbrio parcial.

\subsection{Metodologia}

O modelo de equilíbrio parcial escolhido geralmente assume que os produtos são diferenciados por país fornecedor, e com base nas equações de oferta de exportação e de demanda de importação derivam-se as expressões algébricas utilizadas na estimação dos impactos comerciais. O efeito total sobre as exportações pode ser dividido em duas partes: redução (destruição) de comércio e desvio de comércio (Cline et al., 1978; Laird e Yeats, 1986; Erzan e Yeats, 1992).

A redução (destruição) de comércio corresponde à queda das importações provenientes do Brasil antes, sendo beneficiadas pelo SGP, e que substituíam a produção doméstica norte-americana, relativamente ineficiente. A equação da destruição de comércio pode ser expressa da seguinte forma: ${ }^{9}$

$$
R_{c i}=M_{S G P i}{ }^{*} E_{m i} * \frac{\Delta P_{S G P i}}{P_{S G P i}} *\left[1-\frac{E_{m i}}{E_{x i}}\right]
$$

onde:

$R C_{i}=$ redução (destruição) de comércio ou diminuição das importações norte-americanas do Brasil no SGP do produto $i$;

$M_{S G P i}=$ valor das importações provenientes do Brasil no SGP, no período-base do produto $i$;

$E_{m i}=$ elasticidade-preço das importações do produto $i$;

$P_{S G P i}=$ preço das importações do Brasil no SGP do produto $i$;

$E_{x i}=$ elasticidade-preço das exportações do Brasil do produto $i$.

A falta de informações sobre a elasticidade-preço das exportações é uma das principais dificuldades na aplicação desse modelo. Na maioria dos casos, supõe-se que é infinita, o que implica um custo marginal constante no país exportador. Alguns autores preferem atribuir um valor "razoável" para esse parâmetro e efetuar exercícios com valores levemente superiores e inferiores para testar a sensibilidade dos resultados. Por exemplo, Hoekman, Francis e Olarreaga (2002) atribuem o valor de 0,5 à elasticidade de expor- 
tação para todos os países sob análise (EUA, Canadá, Japão e União Europeia).

Neste trabalho, como não é elevada a participação das exportações brasileiras no SGP-EUA no total das suas vendas externas, a elasticidade de oferta de exportação foi considerada infinita. Assumindo essa suposição, a equação de redução de comércio passa a ser expressa como:

$$
R_{c i}=M_{S G P i}^{*} E_{m i}{ }^{*} \frac{\Delta P_{S G P i}}{P_{S G P i}}
$$

Com o fim do SGP, o produto brasileiro que não pagava tarifa passa a incorrer nesse custo. Logo, há uma variação no preço equivalente à própria tarifa, que, multiplicado pela elasticidade-preço da importação e pelas importações no ano-base, resulta em uma redução das importações norte-americanas originárias do Brasil.

O desvio de comércio representa a queda nas importações dos EUA provenientes do Brasil que sem o SGP passam a ter um preço maior em relação aos demais fornecedores externos do que quando eram beneficiadas com o SGP. Esse efeito pode ser expresso como:

$$
D C_{i}=\frac{M_{S G P_{i}}{ }^{\star} M_{R M_{i}}{ }^{\star} E_{S_{i}}{ }^{\star} \Delta\left(\frac{{ }_{S G P_{i}}}{P_{R M_{i}}}\right)}{M_{S G P_{i}}+M_{R M_{i}}+M_{S G P_{i}}{ }^{\star} E_{S_{i}}{ }^{\star} \Delta\left(\frac{P_{S G P_{i}}}{P_{R M_{i}}}\right)}
$$

onde:

$D C_{i}=$ desvio de comércio do produto $i$;

$M_{R M_{i}}=$ importações do resto do mundo do produto $i$, no período-base;

$E_{S_{i}}=$ elasticidade de substituição do produto $i$;

$P_{R M_{i}}=$ preço das importações do resto do mundo do produto $i$.

Os demais símbolos foram definidos anteriormente.

A interpretação dessa expressão é simples: o aumento da tarifa, exclusivamente sobre os produtos provenientes do Brasil, altera o seu preço em 
relação às importações do resto do mundo, o qual, multiplicado pela elasticidade de substituição e dada a proporção das importações do Brasil e a dos fornecedores do resto do mundo, provoca uma diminuição das importações brasileiras.

A elasticidade de substituição mede o quanto as importações norte-americanas serão desviadas do Brasil para outros exportadores do resto do mundo, em função da variação de preço relativo causado pelo aumento da tarifa sobre os produtos brasileiros.

\subsection{Fonte dos dados}

O modelo foi aplicado para todos os produtos da pauta de importação do SGP-EUA provenientes do Brasil, tendo como base os valores anuais médios no período 2004-2006, ${ }^{10}$ a oito dígitos da classificação HTSUS. Posteriormente, seus resultados foram agregados por setor.

Os dados de importações CIF (Cost, Insurance and Freight) dos EUA foram obtidos do International Trade Commission - ITC Trade Dataweb. Para apresentar o impacto sobre as exportações brasileiras em valor FOB (Free on Board), foram deduzidas as despesas de seguro, frete e outros custos.

As importações norte-americanas dos demais países (resto do mundo) correspondem às importações totais, com e sem benefício do SGP, deduzidas das importações provenientes do Brasil sob o SGP.

As elasticidades de substituição foram obtidas em Gallaway, McDaniel e Rivera (2003). Como as elasticidades estão disponíveis na Standard Industrial Classification (SIC) a quatro dígitos, esses setores foram compatibilizados com os produtos a oito dígitos do HTSUS. As elasticidades-preço de importação foram disponibilizadas por Hoekman, Francis e Olarreaga (2002). O apêndice apresenta a estatística descritiva das elasticidades por setor.

A tarifa ad valorem foi calculada pelo quociente entre o valor do imposto de importação pago nas compras externas dos EUA sem benefício fiscal e o valor das importações FOB. ${ }^{11}$

\subsection{Análise dos resultados}

As estimativas obtidas indicam que a eventual exclusão do Brasil no SGPEUA provocará uma queda nas exportações anuais de cerca de US\$ 402,7 milhões, sendo US\$ 236 milhões de destruição de comércio e US\$166,7 mi- 
Tabela 5: Efeito total da perda anual das exportações brasileiras, por setor (US\$ milhões)

\begin{tabular}{|c|c|c|c|c|c|}
\hline Setor & Descrição & $\begin{array}{l}\text { Redução } \\
\text { comércio }\end{array}$ & $\begin{array}{c}\text { Desvio } \\
\text { comércio }\end{array}$ & $\begin{array}{l}\text { Efeito } \\
\text { total }\end{array}$ & $\begin{array}{c}\text { Parcela } \\
\text { no total }(\%)\end{array}$ \\
\hline 1 & Produtos do reino animal & 0,1 & 0,1 & 0,2 & 0,0 \\
\hline 2 & Produtos do reino vegetal & 1,2 & 1,9 & 3,1 & 0,8 \\
\hline 3 & Óleos animais ou vegetais & 0,2 & 0,1 & 0,3 & 0,1 \\
\hline 4 & Alimentos, bebidas e fumos & 6,8 & 6,4 & 13,2 & 3,3 \\
\hline 5 & Produtos minerais & 0,3 & 0,2 & 0,5 & 0,1 \\
\hline 6 & Produtos químicos & 14,1 & 11,2 & 25,3 & 6,3 \\
\hline 7 & Plásticos e borracha & 15,5 & 26,4 & 41,9 & 10,4 \\
\hline 8 & Peles e couros & 2,7 & 3,1 & 5,8 & 1,4 \\
\hline 9 & Madeira e mobiliário & 34,8 & 38,3 & 73,1 & 18,2 \\
\hline 10 & Celulose e papel & 0 & 0 & 0 & 0,0 \\
\hline 11 & Têxtil e vestuário & 2,7 & 1,7 & 4,4 & 1,1 \\
\hline 12 & Calçados & 0 & 0 & 0 & 0,0 \\
\hline 13 & Cerâmica e vidro & 14,3 & 7,9 & 22,2 & 5,5 \\
\hline 14 & Pérolas e metais preciosos & 6,4 & 3,2 & 9,6 & 2,4 \\
\hline 15 & Metais & 43,9 & 21,3 & 65,2 & 16,2 \\
\hline 16 & Máquinas e equipamentos & 55,7 & 24,4 & 80,1 & 19,9 \\
\hline 17 & Material de transporte & 32,5 & 15,8 & 48,3 & 12,0 \\
\hline 18 & Aparelhos de ótica e de precisão & 1,4 & 0,7 & 2,1 & 0,5 \\
\hline 19 & Armas e munições & 0,5 & 0,7 & 1,2 & 0,3 \\
\hline \multirow[t]{2}{*}{20} & Diversos & 2,9 & 3,3 & 6,2 & 1,5 \\
\hline & Total & 236,0 & 166,7 & 402,7 & 100,0 \\
\hline
\end{tabular}

Fonte: Usitc. Elaboração própria.

lhões de desvio de comércio, no total correspondente a 11,5\% do total exportado médio no período 2004-2006, sob aquele regime.

A tabela 5 apresenta a redução nas exportações brasileiras por setor. Observa-se que $76,7 \%$ do total das perdas seriam procedentes de cinco setores: máquinas e equipamentos (19,9\%), madeira e mobiliário (18,2\%), metais $(16,2 \%)$, material de transporte (12\%) e plásticos e borracha $(10,4 \%)$.

Nota-se também que, em todos os setores, o impacto decorrente da redução do comércio é superior ao desvio de comércio. Esses resultados mostram que a saída do Brasil no SGP dos EUA teria um efeito mais favorável aos produtores norte-americanos do que aos exportadores de países não beneficiados pelo programa.

Como é conhecido, as estimativas obtidas dependem fundamentalmente das elasticidades escolhidas. Para verificar se eventuais erros de medida nes- 
Tabela 6: Teste de sensibilidade, acréscimo e redução de $\mathbf{2 0} \%$ das elasticidades, por setor e total (US\$ milhões)

\begin{tabular}{|c|c|c|c|c|}
\hline Setor & Descrição & Elasticidade 0,8 & $\begin{array}{l}\text { Efeito total } \\
\text { Elasticidade }\end{array}$ & Elasticidade 1,2 \\
\hline 1 & Produtos do reino animal & 0,2 & 0,2 & 0,2 \\
\hline 2 & Produtos do reino vegetal & 2,5 & 3,1 & 3,7 \\
\hline 3 & Óleos animais ou vegetais & 0,2 & 0,3 & 0,4 \\
\hline 4 & Alimentos, bebidas e fumos & 10,6 & 13,2 & 15,8 \\
\hline 5 & Produtos minerais & 0,4 & 0,5 & 0,6 \\
\hline 6 & Produtos químicos & 20,2 & 25,3 & 30,4 \\
\hline 7 & Plásticos e borracha & 33,5 & 41,9 & 50,3 \\
\hline 8 & Peles e couros & 4,6 & 5,8 & 7,0 \\
\hline 9 & Madeira e mobiliário & 58,5 & 73,1 & 87,7 \\
\hline 10 & Celulose e papel & 0,0 & 0,0 & 0,0 \\
\hline 11 & Têxtil e vestuário & 3,5 & 4,4 & 5,3 \\
\hline 12 & Calçados & 0,0 & 0,0 & 0,0 \\
\hline 13 & Cerâmica e vidro & 17,8 & 22,2 & 26,6 \\
\hline 14 & Pérolas e metais preciosos & 7,7 & 9,6 & 11,5 \\
\hline 15 & Metais & 52,2 & 65,2 & 78,2 \\
\hline 16 & Máquinas e equipamentos & 64,1 & 80,1 & 96,1 \\
\hline 17 & Material de transporte & 38,6 & 48,3 & 58,0 \\
\hline 18 & Aparelhos de ótica e de precisão & 1,7 & 2,1 & 2,5 \\
\hline 19 & Armas e munições & 1,0 & 1,2 & 1,4 \\
\hline \multirow[t]{2}{*}{20} & Diversos & 5,0 & 6,2 & 7,4 \\
\hline & Total & 322,2 & 402,7 & 483,2 \\
\hline
\end{tabular}

Fonte: Usitc. Elaboração própria.

ses parâmetros afetaram em demasia os resultados, foi realizado um teste de sensibilidade, multiplicando-se todas as elasticidades por 0,8 e por 1,2, de forma a obter um intervalo com os valores possíveis do efeito total.

A tabela 6 apresenta os limites inferior e superior do efeito total por setor. Observa-se que, com um acréscimo de $20 \%$ nas elasticidades, a perda global nas exportações brasileiras aumentaria para aproximadamente US\$ 483,2 milhões, ao passo que, com uma redução de $20 \%$, a perda diminuiria para US\$322,2 milhões.

Ressalta-se que, na equação de redução de comércio, uma modificação percentual de qualquer variável irá resultar em uma variação idêntica sobre as importações. O mesmo não ocorre com a equação de desvio de comércio. Entretanto, mesmo nesse caso a variação é em torno de $20 \%$ do efeito total. 
Por fim, a importância do SGP dos EUA para o Brasil pode aumentar ou diminuir, dependendo da evolução das negociações multilaterais no âmbito da OMC e da atual política comercial norte-americana de ampliação dos acordos regionais de comércio. De um lado, a redução das barreiras tarifárias na Rodada Doha deverá reduzir os ganhos provenientes dos países beneficiários do SGP e, de outro, os acordos de livre-comércio assinados pelos EUA elevam a importância desse mecanismo para evitar o desvio de comércio contra as nossas exportações.

\section{CONCLUSÕES}

O Brasil exportou cerca de US\$ 3,5 bilhões anuais com o tratamento tarifário favorável propiciado pelo SGP-EUA, no período 2004-2006, o que corresponde a aproximadamente $15 \%$ do valor total exportado para aquele país.

Como o SGP norte-americano é renovado a cada três anos, periodicamente surgem pressões para eliminar o Brasil da lista de países beneficiados, seja por ter alcançado já um nível de desenvolvimento mais elevado, seja por outras questões, como a proteção ao direito de propriedade que ocorreu em 2006. A possibilidade de que esse benefício seja retirado causa bastante apreensão aos exportadores brasileiros, que solicitam que seu governo pressione politicamente os EUA contra essa medida.

Apesar da importância do tema, não há estimativas atualizadas sobre qual seria a perda efetiva nas exportações brasileiras e quais os setores mais prejudicados se eventualmente a ameaça norte-americana se concretizasse.

Este trabalho teve como objetivo calcular o impacto efetivo que a perda do benefício do SGP dos EUA teria sobre as exportações brasileiras totais e por setor, com base no modelo de equilíbrio parcial computável.

As estimativas obtidas indicam uma queda nas exportações anuais entre US\$ 322,7 milhões e US\$ 485,2 milhões, o que representa uma parcela entre $11,4 \%$ e 13,8\% das exportações brasileiras anuais sob o SGP-EUA, no período 2004-2006.

Os setores mais prejudicados seriam o de máquinas e equipamentos, madeira e mobiliário, metais, material de transporte e plástico e borracha, cuja perda corresponderia a $76,7 \%$ do total. 


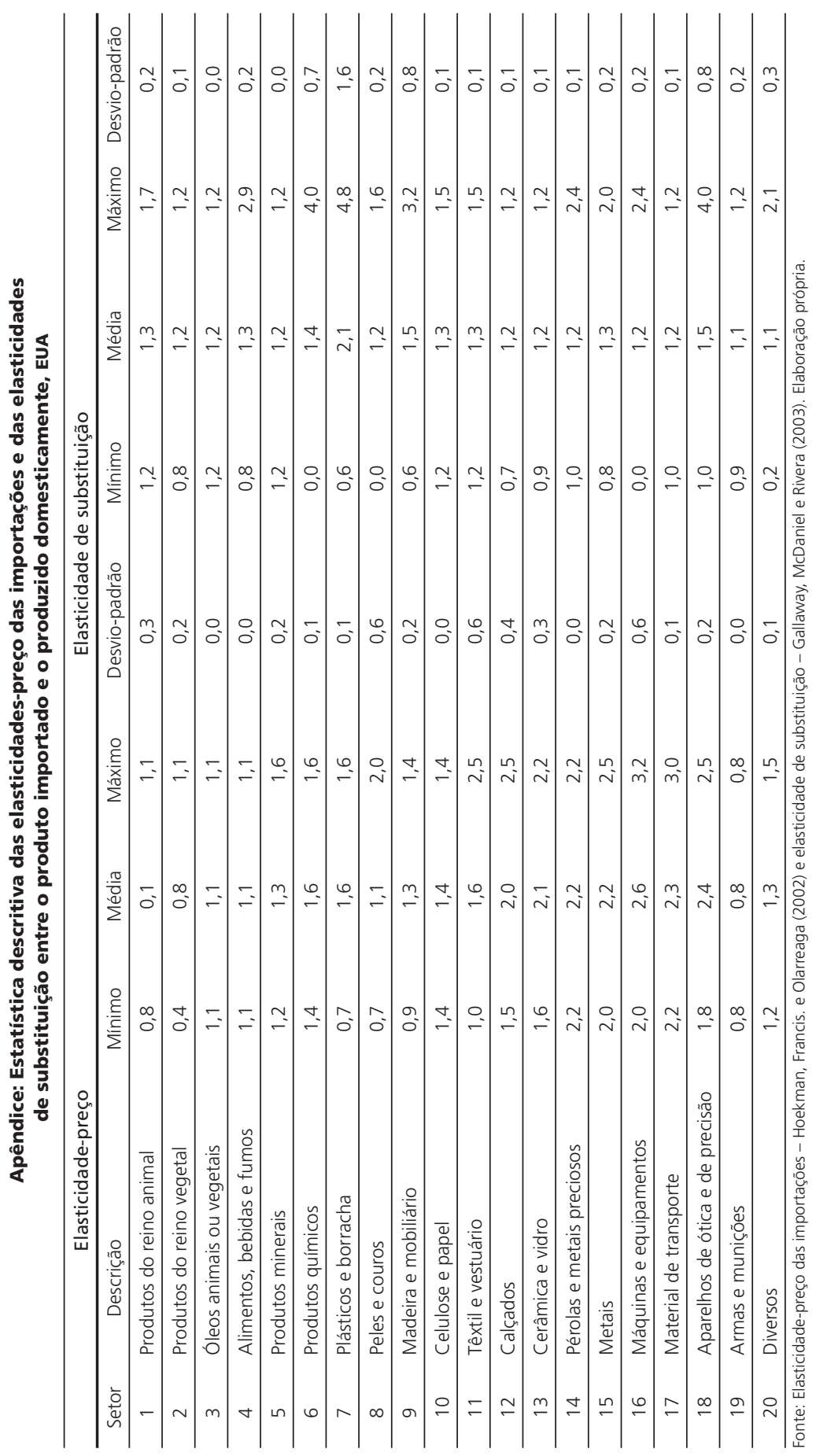




\section{NOTAS}

1. Além do SGP, existem outros programas de preferências tarifárias concedidas de forma unilateral: Caribbean Basin Initiative (CBI), Andean Trade Preference Act (ATPA), Canadian Trade, Industrial Cooperation Programme (Caribcan), African Growth Opportunity Act (AGOA) e Everything But Arms (EBA).

2. United States Trade Representative (USTR, 2007) apresenta uma lista de todas as exigências para que um país possa ser elegível no SGP.

3. A petição do IIPA afirma que as perdas estimadas para 2003, devido à pirataria de materiais com copyright no país, foram de US\$ 785 milhões, representando o maior prejuízo no hemisfério.

4. A provisão do "Special 301" do Trade Act de 1974 exige que o USTR identifique os países estrangeiros que negam proteção adequada ao direito de propriedade intelectual (DPI) ou que impedem o acesso "justo" aos seus respectivos mercados. O Special 301 Report é uma avaliação anual conduzida pelo USTR, na qual alguns países são enquadrados em uma das duas listas: a Priority Watch List e a Watch List. Ambas as listas apresentam países com problemas em relação à proteção ao DPI, mas a primeira engloba os casos considerados mais sérios.

5. Há, no entanto, algumas exceções a essa regra. Alguns produtos têxteis são elegíveis quando o país beneficiário assina um acordo com os EUA e certifica que os produtos provenientes do país beneficiário são artesanais.

6. Como custo direto de processamento, podem-se incluir todos os custos diretamente incorridos ou facilmente alocados nos custos de elaboração, de produção, de manufatura ou de manuseio do produto.

7. Esse é o valor de referência para a Revisão Anual de 2006, sendo elevado anualmente em US\$ 5 milhões.

8. O grau de utilização é levemente inferior ao estimado por Takatsu (2008).

9. A derivação detalhada é encontrada em Laird e Yeats (1986).

10. A média de três anos foi escolhida para evitar que as flutuações atípicas nas exportações que podem ocorrer eventualmente em um determinado ano afetem as estimativas. O período escolhido refere-se aos dados mais recentes, na época da elaboração do trabalho.

11. Nos EUA, a tarifa é aplicada sobre o valor FAS (mercadoria disponível no porto do país exportador ao lado do navio). O valor da importação utilizado no cálculo da tarifa foi o valor FOB. Assim, como o valor da exportação FOB é maior do que o valor da exportação FAS (pois no primeiro o exportador tem o custo adicional de disponibilizar a mercadoria sobre o navio), a tarifa ad valorem calculada é inferior à tarifa legal norte-americana. Não obstante, essa diferença não é significativa.

\section{REFERÊNCIAS BIBLIOGRÁFICAS}

BALDWIN, R.; MURRAY, T. MFN Tariff reductions and developing country trade benefits under the GSP. Economic Journal, v. 87, n. 345, p. 30-46, mar. 1987. 
BROWN, D. General equilibrium effects of the US generalized system of preferences. Southern Economic Journal, v. 54, n. 1, p. 27-47, jul. 1987.

CLINE, R. W. et al. Trade Negotiations in the Tokyo Round: a quantitative assessment. Washington, D.C: The Brookings Institution, 1978.

DEAN, J. M.; WAINIO, J. Quantifying the Value of U.S. Tariff Preferences for Developing Countries. Washington, D.C.: World Bank, aug. 2006. 39p (Policy Research Working Paper n. 3.977). $39 \mathrm{p}$.

DEVAULT, J. Competitive need limits and the US generalized system of preferences. Contemporary Economic Policy, v. 14, n. 4, p. 58-65, oct. 1996.

ERZAN, R.; YEATS, A. Free Trade Agreements with the United States: What's in it for Latin America? Washington, D. C.: World Bank, January 1992. 74 p. (Policy Research Working Paper n. 827).

GALLAWAY, M.; MCDANIEL, C.; RIVERA, S. Short-run and long-run industry-level estimates of U.S. Armington Elasticities. North American Journal of Economics and Finance. v. 14, n. 1, p. 49-68, 2003.

GUTIERREZ, M. B. Tratamento preferencial tarifário para países em desenvolvimento: o caso Brasil - EUA. Revista Brasileira de Comércio Exterior, n. 7, p. 1-8, set./out., 1986.

HARRISON, G. W. et al. Políticas de comércio regionais, multilaterais e unilaterais do Mercosul para o crescimento econômico e a redução da pobreza no Brasil. Pesquisa e Planejamento Econômico, v. 33, n.1, p. 1-60, abr. 2003.

HOEKMAN, B.; FRANCIS, NG.; OLARREAGA, M. Eliminating excessive tariffs on exports of least developed countries. World Bank Economic Review, v. 16, n. 1, p. 1-21, 2002.

INTERNATIONAL TRADE COMMISSION - ITC Trade Dataweb (www.itc.gov)

LAIRD, S.; YEATS, A. The UNCTAD Trade Policy Simulation Model. Geneva: Unctad, oct. 1986. 38 p. (UNCTAD Discussion Paper, n. 19).

MCDANIEL, C. A.; AGAMA, L. The Nafta preference and US-Mexico trade. World Economy, v. 26, n. 7, p. 939-856, jul. 2003.

SEYOUM, B. US trade preferences and export performance of developing countries: evidence from the generalized system of preferences. International Business Review, v. 15, n. 1, p. 68-83, February 2006.

TAKATSU, A. C. A importância do Sistema Geral de Preferências (SGP) dos Estados Unidos para o Brasil. Nota Técnica n. 47. Brasília: Departamento de Negociações Internacionais, Secretaria do Comércio Exterior, Ministério do Desenvolvimento. Indústria e Comércio Exterior, mar. 2008.

USTR - United States Trade Representative. US Generalized System of Preferences Guidebook. Washington D.C. feb. 2007, 32p. 
